\title{
A UTILIZAÇÃO DE RECURSOS TELEMÁTICOS EM PROJETOS DE APRENDIZAGEM
}

Júlio César Castilho Razera

Universidade Estadual do Sudoeste da Bahia, Brasil

\section{ESCOLAS E JOVENS: A TELEMÁTICA COMO FACILITADORA DE UMA APROXIMAÇÃO POSSÍVEL}

A utilização de recursos telemáticos em projetos de aprendizagem abre perspectivas de mudanças na escola, tanto institucionais como pedagógicas, aproximando-a das expectativas dos adolescentes e dos jovens naquilo que pode ser oferecido a eles.

Os multimeios tecnológicos de informação e comunicação potencialmente oferecem a esses adolescentes e jovens espaços de agrupamentos dentro de uma faixa com dois pólos antagônicos, possibilitando a participação deles em ociosidades virtuais alienantes ou até em interações sociais reais capazes de trazêlos ao pertencimento e interferências no mundo real. O posicionamento de nossos alunos nessa faixa de possibilidades, entre um agrupamento e outro, depende de muitas variáveis, mas também depende de como a escola vem utilizando seus recursos tecnológicos para transformá-la, ao mesmo tempo, em ambiente agradável aos jovens e de favorecimento à aprendizagem significativa. As novas tecnologias de informação e comunicação estão "transformando profundamente as sociedades contemporâneas e, em particular, os processos educativos" (Echeverría, 2000), apresentando potencial para tornar a educação mais significativa, mas desde que seja dada oportunidade aos alunos de se envolverem em atividades significativas e autênticas e/ou responder a desafios e problemas. Devem, portanto, constituírem-se ferramenta ao serviço do processo de ensino-aprendizagem e instrumento que propicia resolver problemas e desenvolver projetos, favorecendo a articulação entre diversas áreas do conhecimento e proporcionando a produção de novos conhecimentos.

Os recursos telemáticos devem, como menciona Butter (2004), impulsionar necessidades de reenfocar o currículo, com a busca de novas metodologias que conduzam e influenciem a geração de sujeitos autônomos. O sistema educacional brasileiro, apesar das críticas, apresenta-se dentro desse enfoque, pois não está fechado às necessidades humanas e às possíveis mediações tecnológicas. As leis educacionais e os Parâmetros Curriculares Nacionais amparam possibilidades de avanços, inclusive em ações pedagógicas contextuais, nas quais, atualmente, a utilização das tecnologias de informação e comunicação e as relações humanas na educação aparecem em muitas discussões.

O presente artigo, originado de um trabalho monográfico, apresenta um viés reflexivo sobre limites e perspectivas práticas da telemática em projetos de aprendizagem, tendo sido delineado com aporte teórico e acompanhamento participativo de um fórum de discussões com um grupo de 30 Assistentes Técnicos Pedagógicos (ATP), dos Núcleos Regionais de Tecnologia Educacional do Estado de São Paulo (NRTE), no fórum do ambiente virtual eProinfo (ambiente de Educação a Distância do Departamento de Informática Educacional / MEC), em curso de Especialização em Informática Educacional, com a orientação de professores da Universidade Federal do Espírito Santo. Sendo os Assistentes Técnicos Pedagógicos, 
participantes do fórum, profissionalmente experientes na formação continuada e acompanhamento de professores da rede pública paulista no desenvolvimento de projetos em informática educacional.

\section{INFORMAĈ̃O E CONHECIMENTO: PRESSUPOSTOS BÁSICOS PARA A DISCUSSẢO}

Com a difusão da telemática, um grande fluxo de informação está potencialmente acessível a todos, seja com ou sem procedência e confiabilidade. A velocidade quase instantânea das informações que circulam no mundo atual faz surgir discussões sobre a inserção e o papel da escola nesse processo. Será que a escola perde espaço com o advento das novas tecnologias de informação e comunicação? E o professor, será gradualmente substituído pela "inteligência artificial" das máquinas? É consenso entre pesquisadores que atualmente não cabe mais na educação escolar a simples informação ou transmissão vertical de conteúdo pelos professores, como se os alunos fossem meros receptores. Em razão deste e de outros pressupostos, vimos, com o passar do tempo, aumentar gradativamente a complexidade do trabalho docente e a exigência sobre o professorado, o que vem reforçar ainda mais a importância e as necessidades da formação continuada dos professores.

O dinamismo na difusão e diversidade de informação tem grande importância, mas por si só não é tão significativo para a aprendizagem, que é um processo desenvolvido internamente pela interconexão das representações mentais de cada sujeito. Apesar de toda essa carga de informação abrir inúmeras possibilidades, ainda assim dependerá exclusivamente das necessidades do sujeito e do uso de suas capacidades de aprendizagem, em processos interativos entre as suas representações mentais.

O conhecimento é construído e desenvolvido a partir de uma estrutura cultural, intelectual e cognitiva interna que processa infinitas conexões informativas vindas do exterior, de seu entorno (próximo ou distante de si, em situação real ou virtual, visualizado ou imaginado etc). Devido a inúmeras peculiaridades de cada um, é evidente que as interpretações e construções cognitivas sejam diferentes de pessoa para pessoa. Ocorre, então, um processo idiossincrásico, pois mesmo um único objeto disponível a todos será apenas de cada um, individualmente, esse objeto e os conceitos subjacentes à construção de sua imagem. As informações nem sempre são recebidas e processadas de uma mesma maneira por duas pessoas, cujas estruturas internas diferem. Portanto, as informações, por si só, não implicam diretamente em conhecimento, mas o conhecimento implica em interpretar e compreender as informações que sejam necessárias ao indivíduo. O desenvolvimento da aprendizagem decorre dessa interação entre o meio externo e interno, de processos e feedback de informações e também de experiências concretas que permitam suprir necessidades.

\section{PROJETOS DE APRENDIZAGEM: PERSPECTIVAS, LIMITES E SUPERAÇÃO}

Ao falarmos sobre projetos, não podemos vê-los apenas como simples intenções. Projeto é um processo, um conjunto de ações com participação coletiva da escola e que "adquirem sentido, e se definem como proposta, quando articuladas umas às outras" (Ribeiro, 2000).

Sabemos que trabalhar projetos de aprendizagem exige a participação efetiva dos professores e outros agentes participativos da unidade escolar, porém, exige também definir como esse projeto será contextualizado dentro da escola, por disciplina, interdisciplina ou multidisciplina. Ainda, quais os fatores de apoio e que podem trazer dificuldades no andamento do projeto e como criar situações-problema e mediar soluções possíveis dentro desse mesmo projeto (Jo - ATP participante do fórum). 
Qualquer projeto requer a elaboração de várias etapas, desde o planejamento inicial, no qual todos os envolvidos devem interagir. A partir do levantamento de problemas e diante dos recursos disponíveis, o grupo elabora e põe em prática o projeto. Almeida (2001) alerta que para isso ocorrer o grupo deve estar preparado para trabalhar em equipe, criando-se "um ambiente de confiança, respeito às diferenças e reciprocidade, que encoraja o aluno a reconhecer os seus conflitos e a descobrir a potencialidade de aprender a partir dos próprios erros". Para essa autora, o mesmo deverá ocorrer com o professor "no reconhecimento de suas limitações e na postura de humildade em buscar parcerias". Os alunos não devem, portanto, apenas participar das ações propostas pelos professores, pelos coordenadores ou pelos diretores. Eles devem ser protagonistas também no planejamento e nas propostas iniciais de trabalho que realizarão.

A passividade do aluno no processo educacional deve ser combatida e sempre revertida se essa situação ainda for encontrada. Uma participação mais ativa deles deve ser colocada em prática, com a fundamental e sutil colaboração dos professores na organização das idéias dos alunos. Idéias deles próprios, de suas necessidades, de suas realidades. Lembrando que as tecnologias são, muitas vezes, melhor trabalhadas pelos alunos do que pelos professores, facilitando o caminho de projetos inteiramente protagonizados por eles.

Sem contar que essa estratégia acaba também incidindo sobre a metacognição, termo utilizado pela 1a vez na década de 1970 pelo psicólogo John Flavell e que significa o conhecimento que o indivíduo tem dos próprios processos cognitivos" (Valente, 1989), ou seja, traz maiores possibilidades do aluno entender melhor o seu próprio processo de aprendizagem e as possibilidades reais de intervenções na sociedade da qual faz parte. Segundo consta em Figueiredo e Barros (2002), as atividades de aplicação na sua verdadeira essência não podem resumir-se ao adestramento, elas têm que ser verdadeiros despertadores da atividade cognitiva dos alunos e professores, pois "a metacognição passa pela aquisição de hábitos e processos de trabalho" (Figueiredo \& Barros, 2002). O grande desafio "é ajudar o aluno a utilizar-se de forma consciente, produtiva e racional o seu potencial de pensamento - ensinar a pensar - bem como, a tornar-se consciente das estratégias de aprendizagem a que recorre para construir (reconstruir) conceitos científicos" (Santos,1998).

A aprendizagem cooperativa exige dos envolvidos na aprendizagem constante negociação, tomada de decisão em grupo, responsabilidade do aprendiz pelo seu aprendizado e pelo do grupo, construção de uma inteligência coletiva, tolerância e convivência com diferenças, ações conjuntas e coordenadas, além de outros fatores. A aprendizagem cooperativa vai sendo edificada através das diferenças individuais, a partir da reflexão e interação dos envolvidos e da construção social do conhecimento (Ro - ATP participante do fórum).

Os alunos criam oportunidades de aprendizagem a partir de seus próprios interesses e dependendo do nível etário poderá haver maior ou menor envolvimento deles. Seria sem dúvida desejável que eles assumissem todas as etapas, todo o ciclo do projeto, um projeto orientado por e para os alunos, nas definições de tema/assunto, definição da questão ou do problema a ser resolvido pelo projeto, no estabelecimento do plano para atingir os objetivos, definição dos recursos, na apresentação dos resultados e ainda na avaliação. Envolver os alunos no planejamento do projeto ajuda-os a empenharem-se na sua própria aprendizagem. Contudo, pode-se também trabalhar em projetos orientados pelo professor, com intervenções no processo, mas evitando a perda de autonomia dos alunos. A intervenção poderá ser feita, por exemplo, na definição da questão/problema ou no plano de investigação. O grau de intervenção poderá ser em razão das necessidades dos alunos, pois o caminho escolhido por um grupo pode ser diferente daqueles escolhidos por outros grupos, necessitando, como sugerido pelo Comitê para Democratização da 
Informática de São Paulo (2002), "de orientação para o percurso [e] o grupo necessita acreditar nas suas potencialidades para que possa refletir, criar, descobrir, crescer e desenvolver-se na trajetória da construção do seu próprio conhecimento".

Os projetos possibilitam o desenvolvimento de atividades com a aplicação de um ou mais recursos, que serão adequados para cada contexto ou estratégia utilizada. E não são poucas as potencialidades desses recursos:

A Internet e seus serviços com as suas potencialidades ao nível da pesquisa de informação, comunicação e partilha de conhecimento; o processador de texto, ferramenta básica no que se refere à produção de documentos escritos; a folha de cálculo, no tratamento de dados e sua representação gráfica; a base de dados, como dispositivo de organização e gestão de informação; o recolhimento e tratamento de imagem digital; a apresentação eletrônica da informação; a edição eletrônica e mesmo a produção/edição de vídeo digital, constituem veículos de construção de conhecimento, de partilha e de comunicação indispensáveis na sociedade atual (Solowa,1993).

Mais especificamente existe uma variedade cada vez maior no mercado de software educativo, que com seus diferentes temas ou abrangências acabam servindo a múltiplos fins, cabendo ao professor a análise e pertinência do mesmo.

Pensemos na potencialidade de trabalho entre alunos e professores em projetos com software educativo. Na ocorrência, por exemplo, de um processo de permuta e parceria no ensino e aprendizagem entre eles em relação a outros softwares que conhecem ou queiram conhecer. Será que é difícil imaginarmos professores desenvolvendo projetos propostos pelos alunos? E quanto à possibilidade desses parceiros discutirem juntos os conceitos, conteúdos, ideologias, interfaces etc. dos softwares?

Todo tipo de software necessita de muita reflexão na sua utilização para não ser apenas mais um instrumento em favor da educação tradicional, principalmente o tutorial, ou seja, "aquele que dirige o estudante na aquisição de conhecimento", de acordo com a classificação dada por Taylor (1980). Cabe ao professor direcioná-lo de modo conveniente ao processo de aprendizagem, dentro do currículo e do programa desenvolvidos por ele.

Podemos analisar e testar o potencial dos softwares em diversas situações, mas o que deve prevalecer, no caso de sua utilização ter fins pedagógicos, é sua adequação àação que se deseja implementar. Nesse caso, o papel do educador é essencial. Software considerado excelente pode não trazer os resultados esperados devido a uma utilização pouco criativa, ao passo que um software simples, em muitos casos, pode ser um bom instrumento de suporte àaprendizagem (Su - ATP participante do fórum).

Assim como o livro didático tem uma determinada concepção pedagógica de uso, o mesmo ocorre com os softwares educacionais. Na prática pedagógica não existe um determinado tipo de software perfeito, que por si só, e sem a intermediação do professor (daí o repensar constante sobre seu papel), dê conta do complexo processo de aprendizagem dos alunos. Como, quando e por que o software deve ser utilizado pelo professor formam, na nossa opinião do grupo de Assistentes Técnicos Pedagógicos especialistas, o conjunto de perguntas básicas dessa discussão. Todos os tipos de softwares educativos (tutoriais, de autoria ou de simulação), mesmo com as falhas que possam apresentar na interface ou nos erros conceituais, se trabalhados de maneira consciente, podem ser de grande auxílio no processo de ensino e de aprendizagem. O papel do professor como mediador do processo continua fundamental. Para um trabalho de eficácia, o professor deve ter consciência pedagógica e ideológica dos recursos que têm em suas mãos. Consciência das funções pedagógicas no âmbito dos objetivos a serem atingidos e processos nos quais estamos inseridos e desejamos desenvolver para ampliar as possibilidades de avanços na 
estrutura cognitiva dos alunos. Consciência do papel ideológico em razão das possibilidades da alienação e exclusão social serem ampliadas, pois, como menciona Dupas (2000), "o desenvolvimento vertiginoso de softwares, a difusão maciça da informática, o computador pessoal e os kits para instalação de programa foram um instrumento de rápida implantação de novos parâmetros para o exercício da liderança tecnológica, do poder e da hegemonia econômica do capitalismo".

Empurrados pela cibernética, vivemos em rápida e constante transformação social, com bruscas interferências não só nos projetos sociais, mas também nas relações subjetivas entre os indivíduos, forçando-nos a agir de maneira, consciente (com autonomia) ou inconsciente (com heteronomia). Profundas mudanças estão ocorrendo em nossas próprias representações de mundo e muitas vezes não percebemos. E esta seria apenas uma de muitas preocupações e discussões filosóficas naquilo que as diferentes interfaces entre homem e máquina podem proporcionar à humanidade e ao indivíduo (Ju - ATP participante do fórum).

Basicamente o papel do professor contemporâneo não se altera, devendo pautar-se na orientação e formação integral dos alunos, servindo-se como facilitador de um ambiente de aprendizagem formal e fundamentando-se na postura, nas atitudes, nos valores e em todos os aspectos inerentes da pessoa humana.

$\mathrm{Na}$ prática docente, as tecnologias da informática ainda podem trazer alguns incômodos aparentemente básicos a professores. Uma das inquietações dos professores está relacionada com a utilização de recursos que os alunos, em geral, têm maior intimidade. Para sanar essas deficiências, as repetidas exigências e o maior contato desses professores com tais recursos, nas várias modalidades de cursos e oficinas oferecidas ou disponíveis, minimizarão o problema. Há também depoimentos de professores revelando casos sobre restrições de acesso ou a falta de vontade e/ou comodismo de diretores em promover estratégias que facilitam a utilização dos recursos tecnológicos disponíveis nas escolas, assim como há reclamações de alunos a professores que têm acesso e não utilizam os recursos. Ou seja, em ambos os casos o maior prejuízo recai sobre os alunos. A orientação repassada pelos Núcleos Regionais de Tecnologia sempre foi direcionada para que não houvesse nenhuma dificuldade no acesso aos recursos, mas que tal acesso viesse sempre precedido de projetos, com a participação extensiva da comunidade escolar.

Sobre a comunidade escolar nesse processo, mencionando mais especificamente os pais, houve relatos de uma percepção negativa deles ao uso das tecnologias de informação e comunicação como ferramenta importante a serviço do processo de aprendizagem de seus filhos. Essa ênfase nos aspectos maléficos, nos faz pensar que os pais também merecem orientações das escolas de seus filhos quanto ao uso pedagógico das tecnologias. Mas o que fazer quando há distanciamento entre a escola e sua comunidade?

O nível de participação da comunidade depende de cada região, ou mais especificamente de cada escola. Escolas acompanhadas pelo grupo de Assistentes Técnicos Pedagógicos apresentaram um nível baixo de envolvimento dos pais. Talvez não pela predisposição deles, mas pela omissão e falta de interesse da administração escolar. Será que os pais são incentivados a participarem? Se sim, em que nível?

A escola socialmente responsável é aquela que possui a capacidade de ouvir os diferentes interesses da sua comunidade como, por exemplo, os professores, alunos, direção, funcionários, pais, instituições auxiliares (Grêmio Estudantil, APM, Conselho de Escola) e comunidade, conseguindo incorporá-los no planejamento de suas atividades, buscando atender às demandas de todos (Fa - ATP participante do fórum). 


\section{APLICAÇÃO: ENTRE A UTOPIA E A REALIDADE}

Alunos, professores, gestores educacionais e comunidade de pais colaborando, todos juntos, na elaboração da proposta pedagógica da escola, na qual estarão inseridos projetos que integram recursos telemáticos para transformar o ambiente escolar numa rede dinâmica de conhecimento, capaz de ultrapassar seus muros e atingir outras comunidades que fizeram o mesmo trabalho.

O modelo parece simples, mas exige uma ruptura da estrutura estática atual da escola e a "necessidade de se romper com modelos tradicionais para que se alcancem os objetivos propostos" (Brasil, 1999).

A tarefa básica, portanto, consiste em transformar a escola em ambiente dinâmico, caracterizado por uma estrutura de rede de conhecimentos a partir de projetos múltiplos que estimulem a resolução de problemas e a tomada de decisões, diante de problemas previamente levantados e priorizados por toda a comunidade escolar. Essa rede inicialmente pode ser local, na própria unidade escolar, mas também poderá se estender para outras escolas da mesma cidade, ou até mesmo de outras regiões ou países. $O$ instrumento para isso é a informática, com páginas na internet produzidas para esse fim, com espaços múltiplos para a divulgação de projetos, das pesquisas em andamento e das discussões dos resultados. Essa estratégia é defendida por Moran (2002):

uma das formas mais interessantes de trabalhar hoje colaborativamente é criar uma página dos alunos, como um espaço virtual de referência, onde vamos construindo e colocando o que acontece de mais importante no curso, os textos, os endereços, as análises, as pesquisas. Pode ser um site provisório, interno, sem divulgação, que eventualmente poderá ser colocado a disposição do público externo. Pode ser também um conjunto de sites individuais ou de pequenos grupos que se visibilizam quando os alunos acharem conveniente. Não deve ser obrigatória a criação da página, mas incentivar a que todos participem e a construam. O formato, colocação e atualização pode ficar a cargo de um pequeno grupo de alunos (Moran, 2002).

Além dessa ferramenta, ainda há a possibilidade de, a cada período (final de semestre, por exemplo), ocorrer eventos que possibilitem a divulgação e a discussão dos trabalhos desenvolvidos. Isso pode ser feito através de um congresso escolar ou interescolar, seminários, exposições, oficinas, exposição de pôsteres etc. Jornais, circuito interno de TV e rádio também são outras possibilidades.

Alunos de cada classe terão oportunidade de ingressar em grupos de seu interesse. Esses grupos serão formados de acordo com as áreas sugeridas nos Parâmetros Curriculares Nacionais. Em cada uma dessas áreas, os temas dos projetos serão discutidos, assim como o planejamento, as estratégias, ações, avaliações etc. Sempre com a participação dos alunos e dos professores (um pode ser coordenador/orientador). Deve haver intercâmbio entre alunos de mesma série. $E$ os alunos terão espaços e recursos para o desenvolvimento de suas pesquisas. Esses recursos serão administrados pelos gestores/professores (internet, TV, webcam, rádio, jornal, microcomputadores pessoais, vídeocassete, filmadora, máquina fotográfica, scanner, impressora, laboratórios, bibliotecas etc.)

Os professores ficarão a disposição dos alunos, para dirimir dúvidas e orientá-los de acordo com a especificidade de sua disciplina. Além disso, oferecerão mini-cursos ou oficinas que auxiliem os diferentes grupos a realizarem os seus trabalhos. Exemplo: professores de português orientarão as técnicas de redação e de linguagem; professores de física, química e biologia orientarão sobre as técnicas e metodologias de pesquisa, professores de artes orientarão sobre os aspectos visuais da apresentação dos trabalhos etc. 
Atuando como Assistente Técnico Pedagógico do Núcleo Regional de Tecnologia Educacional, acompanhei algumas escolas da região de Bauru, interior de São Paulo, que utilizaram estratégias semelhantes. Além de criarem e desenvolverem seus próprios sites, auxiliando no registro e divulgação de seus trabalhos, também interagiam com outras escolas, até mesmo de outros estados e países, na troca de informações e experiências. O que percebi, entretanto, é que a maioria desses trabalhos só vai adiante quando originados por iniciativa dos alunos e quando abraçados por algum professor que entende as possibilidades pedagógicas desse processo. Experiências semelhantes também foram relatadas e comprovadas por colegas de outras regiões.

\section{CONSIDERAÇÕES FINAIS}

Pelas discussões acompanhadas no fórum, parece que um dos desafios atuais da educação é torná-la síncrona com a realidade, exigindo-se compromisso de mudanças para que "a educação do futuro tenha como base a ética", sendo capaz de garantir um mundo mais belo e humano (Morin 2000).

A linha da pedagogia histórico-crítica tem defendido mudanças de postura na escola para tirá-la de seu antiquado papel de reforçar o statu quo de uma estrutura social que é perversa àmaioria das pessoas.

A educação formal é um ambiente importante para o desenvolvimento da aprendizagem cognitiva e para a socialização dos indivíduos, pois tem possibilidades de oferecer e trabalhar a realidade do cenário histórico-crítico que ajudamos a construir e no qual nós vivemos.

As tecnologias surgem de necessidades do ser humano em agilizar ou facilitar determinadas tarefas. Ocorre, entretanto, que o domínio e utilização de tecnologias mais complexas ou sofisticadas ficam, por vários motivos (pelo menos antes de sua popularização ou utilização inicial em alguma instituição), restritos a poucas pessoas. É paradoxal, pois ao mesmo tempo que as tecnologias surgem para facilitar a vida das pessoas, também acabam dificultando o acesso a outras pessoas, aumentando, em muitos casos, o desequilíbrio social. Isso sem contar as dependências e aumento de poder das elites e grandes empresas que dominam as tecnologias em detrimento dos mais pobres que pagam caro pela sua utilização.

A inserção das tecnologias de informação e comunicação na escola não está imune a todos esses e outros aspectos mais específicos, implicando em superação de obstáculos, algumas discussões, intervenções ou esclarecimentos.

No geral, por mais falhas que tenha o nosso sistema educacional, a escola continua sendo um dos mais importantes espaços para o desenvolvimento integral dos jovens. Todo envolvimento do jovem consigo mesmo e com os seus colegas, formando ou não pequenos grupos e tendo que partilhar atividades semelhantes nos mesmos espaços, faz da escola um ambiente que possibilita muito mais do que se observa nos professores individualmente tentando conseguir os "êxitos de aprendizagem" [grifo meu] em suas disciplinas. Muitas escolas, felizmente, têm investido um pouco mais no protagonismo juvenil, incentivando e propiciando maior participação do jovem em diversas atividades que utilizam os recursos da telemática. Afirma Lévy (1998) que "a introdução dos computadores nas escolas pode muito bem prestar-se a debates de orientação, dar margem a múltiplos conflitos e negociações onde técnica, política e projetos culturais misturam-se de forma inextrincável". O computador, complementa Schaff (2000), "é um produto do homem, é parte de sua cultura. Servirá a muitos fins: como supermemória artificial que aliviará bastante a carga de memória humana hoje necessária, tornando assim muito mais fácil o processo de ensino; ou como 
idealizador de novos métodos de conhecimento humano em muitas disciplinas, incluindo aquelas que no início se acreditava estarem fechadas às técnicas informáticas".

A inserção dos recursos tecnológicos no processo educativo amplia as reformulações pretendidas, passando por novas e difíceis fases, que devem ser amplamente discutidas com todos os interessados, incluindo a comunidade escolar.

Alguns pontos que não poderiam faltar nessas discussões:

1) A estrutura da rede mundial de informações (Internet) e suas possibilidades educacionais.

2) Reformulações possíveis nos currículos, para atender as novas exigências.

3) As relações interpessoais no ambiente de aprendizagem.

4) Projetos pedagógicos: aprendizagem por projetos e protagonismo juvenil.

5) As novas funções da escola frente ao mundo globalizado.

6) Aspectos éticos e os valores nos ambientes informatizados.

7) Os atuais organogramas institucionais.

8) As questões ideológicas inerentes às tecnologias na educação.

Nessa linha utópica, muitas seriam as resistências, tanto no aspecto micro quanto no macroestrutural. Entretanto, o tempo, as necessidades naturais e o envolvimento da comunidade, e principalmente dos jovens nos problemas, serviriam como aliadas às mudanças previstas ou, pelo menos, a novas e mais objetivas e conclusivas discussões.

\section{REFERÊNCIAS BIBLIOGRÁFICAS}

ALMEIDA, M. E. Informática e formação de professores. MEC / PROINFO, v.1, Brasília, 2000 [Série de Estudos].

ALMEIDA, M. E. Educação, projetos tecnologia e conhecimento, São Paulo: Proem, 2001.

BRASIL, Ministério da Educação, Secretaria de Educação Média e Tecnológica. Parâmetros Curriculares Nacionais: ensino médio, Brasília: Ministério da Educação, 1999.

BUTTER, C. M.; BARROS, J. O. Currículum cibernético. Disponível em: <http://venado.conce.plaza.cl/ mcareaga/000curr.htm> Acesso em: 10 jun. 2004.

COMITÊ PARA DEMOCRATIZAÇÃo DA INFORMÁtICA DE SÃo PAULO. Disponível em: <http://www.cdisp.org.br/pedagogico/projeto/carac.htm> Acesso em: 25 nov. 2002.

DUPAS, Gilberto. Ética e poder na sociedade da informação. São Paulo: Unesp, 2000.

ECHEVERRÍA, J. Educación y tecnologías telematicas. Revista Iberoamericana de Educación. Organización de Estados Iberoamericanos: Ediciones, n.24, set/dez 2000. Disponível em: <http://www.campusoei.org/revista/rie24.htm> Acesso em: 10 jun 2004.

Figueiredo, F. J. C.; BARRos, J. O. Metacognição: tempo para ouvir a nós próprios. Disponível em: <http://www.ipv.pt/millenium/17_ect10.htm> Acesso em 24 nov. 2002. 
LÉVY, P. As tecnologias da inteligência - o futuro do pensamento na era da informática. São Paulo: Editora 34, 1998.

MORAN, J. M. Ensino e aprendizagem inovadores com tecnologia.. Disponível em: <http://www.eca.usp.br/prof/moran/inov.htm> Acesso em: 28 nov. 2002.

MORIN, E. Os sete saberes necessários à educação do futuro. São Paulo: Cortez, 2000.

RIBEIRO, J. Projeto pedagógico e projeto de informática. Revista Acesso. São Paulo: Fundação para o Desenvolvimento da Educação, n.14, dez 2000, p.35-8.

SANTOS, M. E. (1998). Mudança conceptual na sala de aula. Lisboa: Livros Horizonte.

SCHAFF, Adam. A sociedade informática. São Paulo: Brasiliense, 2000.

SOLOWA, E. Reading and Writing in the 21st Century, EDUCOM Review, v.28, n.1, 1993. Disponível em: <http://www.minerva.uevora.pt/rtic/aprojecto/ap_tic.htm> Acesso em: 26 nov. 2002.

TAYLOR, R.P. The Computer in the School: Tutor, Tool, Tutee. Teachers College Press, New York, 1980

VALENTE, M. et al. A Metacognição. Revista de Educação, v.1, n.3, 1989. 


\title{
Contactar
}

Revista lberoamericana de Educación

\author{
Principal OEI
}

